\title{
Tumor Necrosis Factor-Associated Protein 1 (TRAP1) is Released from the Mitochondria Following 6-hydroxydopamine Treatment
}

\author{
Dong-Ik Shin and Young J. Oh* \\ Department of Systems Biology, Yonsei University College of Life Science and Biotechnology, Seoul, Korea
}

\begin{abstract}
Parkinson's disease (PD) is a common neurodegenerative disorder characterized by progressive degeneration of dopaminergic neurons in the substantia nigra pars compacta. Most cases are sporadic and its etiology is incompletely understood. However, increasing evidence suggests that oxidative stress and mitochondrial dysfunction may be involved in the pathogenesis of Parkinson's disease. The aim of this study was to investigate changes in mitochondrial protein profiles during dopaminergic neuronal cell death using two-dimensional gel electrophoresis in conjunction with mass spectrometry. Several protein spots were found to be significantly altered following treatment of MN9D dopaminergic neuronal cells with 6-hydroxydopamine (6-OHDA). Among several identified candidates, TNF receptor-associated protein 1 (TRAP1), a mitochondrial molecular chaperone, was released from the mitochondria into the cytosol in MN9D cells as well as primary cultures of dopaminergic neurons following 6-OHDA treatment. This event was drug-specific in that such apoptotic inducers as staurosporine and etoposide did not cause translocation of TRAP1 into the cytosol. To our knowledge, the present study is the first to demonstrate the drug-induced subcellular translocation of TRAP1 during neurodegeneration. Further studies delineating cellular mechanism associated with this phenomenon and its functional consequence may provide better understanding of dopaminergic neurodegeneration that underlies PD pathogenesis.
\end{abstract}

Key words: 6-hydroxydopamine, Parkinson’s disease, proteomics, mitochondria, TRAP1

\section{INTRODUCTION}

Mitochondrial dysfunction has long been implicated in the pathogenesis of PD. Several previous studies point to the central role of mitochondria in PD: reduced complex I activity [1-5], reduced mitochondrial membrane potential $(\Delta \Psi \mathrm{m})$ along with increased production of reactive oxygen species (ROS) $[6,7]$,

Received February 14, 2014, Revised February 25, 2014,

Accepted February 26, 2014

${ }^{*}$ To whom correspondence should be addressed. TEL: 82-2-2123-2662, FAX: 82-2-312-5657 e-mail:yjoh@yonsei.ac.kr alterations in mitochondrial fission-fusion events [8,9], and defects in mitochondrial trafficking $[10,11]$. These studies also indicate that many of the PD-related proteins are either located at the mitochondria and/or closely associated with mitochondrial functions [12-16]. Dysregulated accumulation of the misfolded proteins is another feature typically accompanied in patients with PD and experimental models of PD [17]. It has been shown that disturbance or imbalance of such systems as the ubiquitin proteasomal system (UPS) and the heat shock proteins (HSP) are critically involved in the progression of the disease $[18,19]$. Transcriptional analysis of multiple brain regions in PD also indicates the dysfunction of UPS, along with a robust induction of several forms of HSPs is one of the central events during
Copyright $\odot$ Experimental Neurobiology 2014. www.enjournal.org
This is an Open Access article distributed under the terms of the Creative Commons Attribution Non-Commercial License (http://creativecommons.org/licenses/by-nc/3.0) which permits unrestricted non-commercial use, distribution, and reproduction in any medium, provided the original work is properly cited. 
neurodegeneration [20]. In consideration of pathological features of PD including formation of Lewy bodies and Lewy neurites, it is quite obvious that aberrant accumulation of the misfolded proteins is a common event in chronic neurodegenerative disorders including PD. Certainly, this phenomenon indicates that abnormality of protein homeostasis is substantially contributing to the pathogenesis of the disease [18].

Currently, proteomic approaches have been utilized to identify multiple target proteins that potentially associated with disease progression [21-24]. Both fluid and solid tissue samples obtained from experimental models of PD or from patients with PD have been subjected to proteomic analysis [25-28]. So far, quantitative proteomic analyses have been conducted using well-characterized models of PD that are established following treatment with MPTP [29, 30], 6-OHDA [31-34], L-dopa [35], dopamine quinone [27] or lipopolysaccharide [36]. In this study, we specifically attempted to analyze changes in the mitochondrial protein profiles in the MN9D dopaminergic cell line following 6-OHDA treatment. By utilizing the fractionated mitochondrial samples, we attempted to identify the altered mitochondrial proteins via 2-dimensional electrophoresis (2-DE) in conjunction with mass spectrometry. As a result, we initially identified 73 altered proteins in the mitochondria of MN9D cells treated with 6-OHDA. Among these identified potential candidates, we found that TRAP1 is released from the mitochondria into the cytosol. This phenomenon was paralleled with a drug-induced neurodegeneration in MN9D cells as well as primary cultures of dopaminergic neurons. At present, its functional implication is not understood. Further study to delineate the molecular and cellular mechanism underlying the subcellular translocation of TRAP1 may provide a new insight of critical role for the chaperone proteins in the regulation of neurodegeneration.

\section{MATERIALS AND METHODS}

\section{Cell culture and Drug Treatment}

MN9D dopaminergic neuronal cell line was established by somatic fusion between embryonic mesencephalic neurons and N18TG cells. MN9D cells were plated at a density of $1 \times 10^{6}$ on $25 \mu \mathrm{g} / \mathrm{ml}$ poly-D-lysine (Sigma, St. Louis, MO, USA)-coated P-100 culture plate and cultivated in Dulbecco's Modified Eagle's Medium (DMEM; Sigma) supplemented with 10\% heatinactivated fetal bovine serum (FBS; Gibco, Grand Island, NY, USA) in an atmosphere of $10 \% \mathrm{CO}_{2}$ for $2 \sim 3$ days. The medium was subsequently replaced with $\mathrm{N} 2$ serum-free defined medium containing $100 \mu \mathrm{M}$ 6-OHDA, $1 \mu \mathrm{M}$ staurosporine (STS) or 100 $\mu \mathrm{M}$ etoposide (all from Sigma) for the time periods indicated.
If necessary, $1 \mathrm{mM} \mathrm{N}$-acetyl-L-cysteine was also added to the medium. To prepare primary cultures of dopaminergic neurons, the ventral mesencephalon were removed from Sprague Dawley rat embryos at gestation day 14.5 (Orient, Suwon, Korea). Tissues were incubated with $0.01 \%$ trypsin in HBSS for $10 \mathrm{~min}$ at $37^{\circ} \mathrm{C}$ and triturated with a constricted Pasteur pipette. Dissociated cells were plated at $1.0 \times 10^{5}$ cells onto poly-D-lysine and laminin (Invitrogen, San Diego, CA)-double coated Aclar embedding film with a size of $8 \mathrm{~mm}$ in diameter (Electron Microscopy Sciences, Fort Washington, PA). Cultures were maintained at $37^{\circ} \mathrm{C}$ in a humidified 5\% $\mathrm{CO}_{2}$ atmosphere in MEM supplemented with 10\% FBS, $2 \mathrm{mM}$ glutamine and $6.0 \mathrm{mg} / \mathrm{L}$ glucose. At 5 or 6 DIV, cells were washed with MEM and treated with $20 \mu \mathrm{M}$ 6-OHDA.

\section{Cellular Fractionation}

Following drug treatment, MN9D cells were fractionated into the cytosolic and the mitochondrial fractions using a sucrose density gradient method. Briefly, freshly collected cellular lysates were homogenized with a loose pestle homogenizer (Wheaton, USA) at $4^{\circ} \mathrm{C}$ in a buffer containing $10 \mathrm{mM}$ Tris-HCl, $\mathrm{pH} 7.4$, $10 \%$ sucrose and complete protease inhibitor cocktail (Roche, Mannheim, Germany). The homogenate was centrifuge at $600 \times \mathrm{g}$ for $15 \mathrm{~min}$ at $4^{\circ} \mathrm{C}$, and the pellet was discarded. The supernatant containing the mitochondria was subjected to centrifugation at $15,000 \times \mathrm{g}$ for $20 \mathrm{~min}$ at $4^{\circ} \mathrm{C}$. For the cytosolic fraction, the resulting supernatant was further centrifuged at $100,000 \times \mathrm{g}$ for 1 hr at $4^{\circ} \mathrm{C}$. For the mitochondrial fraction, pellet was loaded onto $10 \sim 50 \%$ sucrose gradient in $10 \mathrm{mM}$ Tris- $\mathrm{HCl}$ pH7.4 containing complete protease inhibitor cocktail. Samples were then subjected to an additional centrifugation at $100,000 \mathrm{x}$ g for $2 \mathrm{hr}$ at $4^{\circ} \mathrm{C}$. The brownish band between 40 and 50\% sucrose gradient layer was collected using a constricted pipette tip and again subjected to a centrifugation at $100,000 \times \mathrm{g}$ for $1 \mathrm{hr}$ at $4^{\circ} \mathrm{C}$. The resulting pellet was lysed in a RIPA buffer containing $50 \mathrm{mM}$ Tris- $\mathrm{HCl} \mathrm{pH} \mathrm{7.4,} \%$ NP-40, 0.25\% Na-deoxycholate, 150 mM NaCl, 1 mM EDTA, 0.1\% SDS, and complete protease inhibitor cocktail. This was used as the mitochondrial fraction.

\section{$2-D E$}

All procedures for 2-DE was carried out basically based on our previous report [32]. Following treatment with $100 \mu \mathrm{M} 6-\mathrm{OHDA}$ for various times indicated, MN9D cells were fractionated as described above. Each fractions were solubilized in a sample buffer containing $7 \mathrm{M}$ urea, $2 \mathrm{M}$ thiourea, 4.5\% CHAPS, 40 $\mathrm{mM}$ Tris- $\mathrm{HCl}, 100 \mathrm{mM}$ DTE, $0.002 \%$ BPB, complete protease inhibitor cocktail and 1\% IPG buffer for $\mathrm{pH} 3 \sim 10$ non-linear Immobiline DryStrip (Amersham Biosciences). Protein content 
was determined by Bradford protein assay reagent (Bio-Rad, Hercules, CA, USA) Prior to isoelectric focusing, Immobiline DryStrips $(24 \mathrm{~cm}$ or $7 \mathrm{~cm}$ ) were rehydrated in a sample buffer containing 500 to $1,500 \mu \mathrm{g}$ of the fractionated cellular lysates. Gels were run for a total of $96 \mathrm{kVh}$ for $24 \mathrm{~cm}$ DryStrip or $8.7 \mathrm{kVh}$ for $7 \mathrm{~cm}$ DryStrip using progressively increasing voltage on an Ettan IPGphor (Amersham Biosciences). After equilibration, SDSPAGE was performed on a 10 15\% gradient gel in an Ettan Dalt II System for $24 \mathrm{~cm}$ DryStrip, or on a $8 \%$ gel in a Mini-Protean 3 Electrophoresis Cell (Bio-Rad) for $7 \mathrm{~cm}$ DryStrip. Gels stained with 0.1\% Coomassie Brilliant Blue G-250 were scanned using a densitometer (Powerlook 2100XL, UMAX, USA) and the images were analyzed using the ProteomWeaver software system (Bio$\mathrm{Rad})$. For in-gel digestion, protein spots of interest were manually excised from the Coomassie-stained gels. Gel slices were washed with a buffer containing $25 \mathrm{mM} \mathrm{NH}_{4} \mathrm{HCO}_{3} / 50 \%$ acetonitrile, dried completely using a Speedvac evaporator dryer (BioTron, Korea) and digested with $10 \mu \mathrm{g} / \mathrm{ml}$ trypsin (Promega) in $25 \mathrm{mM}$ $\mathrm{NH}_{4} \mathrm{HCO}_{3}$ at $37^{\circ} \mathrm{C}$ for $18 \mathrm{hr}$. Peptides were solubilized with $0.1 \%$ trifluoracetic acid (TFA), and desalted using an in-house column packed with $\mathrm{C} 18$ porous beads. Bound peptides were eluted in $0.6 \mu \mathrm{l}$ elution buffer containing $1 \mathrm{mg} / \mathrm{ml}$-cyano-4-hydroxycinnamic acid solution in $60 \%$ acetonitrile $/ 0.1 \%$ TFA and spotted onto a MALDI plate (Applied Biosystems). Peptide mixtures were analyzed by a 4700 Proteomics Analyzer (Applied Biosystems) and peptide masses were matched with the theoretical peptide masses of all proteins from all species using the NCBI or SWISS-PROT database.

\section{Immunoblot analysis}

Following drug treatment, MN9D cells were lysed on ice in a RIPA buffer containing $50 \mathrm{mM}$ Tris- $\mathrm{HCl} \mathrm{pH}$ 7.4, 1\% NP40, 0.25\% Na-deoxycholate, $150 \mathrm{mM} \mathrm{NaCl}, 1$ mM EDTA, 0.1\% SDS, and complete protease inhibitor cocktail. Cells were then homogenized using a $1-\mathrm{ml}$ syringe attached with a 26 -gauge needle. Cellular lysates were centrifuged at $14,500 \times \mathrm{g}$ for $10 \mathrm{~min}$ at $4^{\circ} \mathrm{C}$. The supernatants were collected and quantified using a Bradford protein assay reagent. Following drug treatment, MN9D cells were lysed on ice for $30 \mathrm{~min}$ in PBS containing 1\% Triton X-100 and complete protease inhibitor cocktail. After centrifugation at $15,000 \times \mathrm{g}$ for $30 \mathrm{~min}$ at $4^{\circ} \mathrm{C}, 1 \%$ Triton X-100soluble fractions were collected. The pellets were washed 4 times with PBS containing $1 \%$ Triton X-100 and further solubilized in PBS buffer containing 1\% SDS, $1 \%$ Triton X-100, and complete protease inhibitor for $1 \mathrm{hr}$ at $60^{\circ} \mathrm{C}$. Subsequently, Triton X-100insoluble fractions were collected by centrifugation at $15,000 \times \mathrm{g}$ for $30 \mathrm{~min}$ at $4^{\circ} \mathrm{C}$. For immunoblot analysis, fifty micrograms of protein from each sample were separated on 7 or $8 \%$ SDS-PAGE gels and blotted onto PVDF membranes (Pall Corp., Ann Arbor, MI, USA). Membranes were probed with one of the following primary antibodies: mouse anti-BCKDHA, mouse anti-HCCS, mouse anti-WWP1, mouse anti-NDUFS2, mouse anti-PMPCB, mouse anti-PGAM1; Novus; 1:1000), rabbit anti-ACO2, rabbit anti-VDAC2, rabbit anti-STOML2 (Proteintech; 1:1000), rabbit anti-Cpn 10 (Stressgen; 1:1000), rabbit anti-Erp57, goat antiSOD-1, rabbit anti- $\alpha$-tububin, rabbit anti-Tom 20 (Santa Cruz; 1:1000), mouse anti-Grp75, mouse anti-PTGES, goat anti-DJ1(Abcam; 1:1000), mouse anti-cytochrome c, mouse anti-TRAP1 (BD Biosciences; 1:2000), mouse anti-COXIV (Molecular Probes; 1:1000), rabbit anti-cleaved caspase-3 (Cell Signaling; 1:1000), and mouse anti-GAPDH (Chemicon; 1:3000). After washing with TBS containing $0.1 \%$ Tween-20, cells were incubated with goat anti-rabbit HRP-conjugated antibody (Santa Cruz; 1:3000), goat anti-mouse HRP-conjugated antibody (Santa Cruz; 1:3000), or donkey anti-goat HRP-conjugated antibody (Santa Cruz; 1:20000). Specific bands were detected using enhanced chemiluminescence (ECL; Amersham Pharmacia Biotech, Piscataway, NJ, USA).

\section{Immunocytochemistry}

For a double immunocytochemical labeling, cells were fixed with $4 \%$ paraformaldehyde (EMS, Hatfield, PA, USA) at RT for 10 $\mathrm{min}$ at various time periods after drug treatment. For the images of TRAP1 and cytochrome c, cells were permeabilized with $0.3 \%$ saponin (Sigma) at RT for 10 min followed by blocking in $0.2 \%$ cold water fish gelatin/0.5\% BSA in PBS (PBG) at RT for $30 \mathrm{~min}$. After permeabilization and blocking steps, cells were incubated with a mouse anti-TRAP1 antibody, mouse anti-cytochrome C antibody (BD Biosciences; 1:200) or rabbit anti-Tom20 (Santa Cruz; $1: 200$ ) in $0.2 \%$ PBG overnight at $4^{\circ} \mathrm{C}$. After extensive washing, cells were incubated with Alexa488-conjugated goat anti-rabbit IgG (Invitrogen; 1:200) and Alexa568-conjugated goat anti-mouse IgG (Invitrogen; 1:200) at RT for $1 \mathrm{hr}$. Hoechst 33258 staining (Molecular Probes; $1 \mu \mathrm{g} / \mathrm{ml}$, Eugene, OR, USA) was performed for $10 \mathrm{~min}$ at RT. Slides were mounted with Vectashield mounting medium (Vector Laboratories, Burlingame, CA, USA). Samples were observed under an LSM 510 META confocal laser scanning microscope equipped with epifluorescence and a digital image analyzer (Carl Zeiss, Zena, Germany).

\section{RESULTS AND DISCUSSION}

Our laboratory previously reported that 6-OHDA induces prototypic apoptosis, including cytochrome $\mathrm{c}$ release and caspase activation in MN9D cells as well as primary cultures 
Table 1. Summary of the identified mitochondrial proteins altered after 6-OHDA treatment

\begin{tabular}{|c|c|c|c|c|c|c|}
\hline Spot number & \multicolumn{4}{|c|}{ Protein name $^{\mathrm{a}}$} & Accession number ${ }^{b}$ & Locus \\
\hline 1 & \multicolumn{4}{|c|}{ 2-oxoisovalerate dehydrogenase subunit alpha, mitochondrial precursor } & P50136 & Mt \\
\hline 2 & \multicolumn{4}{|c|}{ Acyl-coenzyme A thioesterase 2, mitochondrial precursor } & Q9QYR9 & Mt \\
\hline 3 & \multicolumn{4}{|c|}{$10 \mathrm{kDa}$ heat shock protein, mitochondrial } & Q64433 & Mt \\
\hline 4 & \multicolumn{4}{|c|}{ Protein disulfide-isomerase A3 precursor } & P27773 & Mt \\
\hline 5 & \multicolumn{4}{|c|}{ Stress- 70 protein, mitochondrial precursor } & P38647 & Mt \\
\hline 6 & \multicolumn{4}{|c|}{ Cytochrome c-type heme lyase } & P53702 & Mt \\
\hline 7 & \multicolumn{4}{|c|}{ Voltage-dependent anion-selective channel protein 2} & Q60930 & Mt \\
\hline 8 & \multicolumn{4}{|c|}{ Prostaglandin E synthase 2} & Q8BWM0 & Mt \\
\hline 9 & \multicolumn{4}{|c|}{ NEDD4-like E3 ubiquitin-protein ligase WWP1 } & Q8BZZ3 & Mt \\
\hline 10 & \multicolumn{4}{|c|}{ NADH dehydrogenase [ubiquinone] iron-sulfur protein 2, mitochondrial precursor } & Q91WD5 & Mt \\
\hline 11 & \multicolumn{4}{|c|}{ Mitochondrial-processing peptidase subunit beta, mitochondrial precursor } & Q9CXT8 & Mt \\
\hline 12 & \multicolumn{4}{|c|}{ Stomatin-like protein 2} & Q99JB2 & Mt \\
\hline 13 & \multicolumn{4}{|c|}{ Electron transfer flavoprotein subunit alpha, mitochondrial precursor } & Q99LC5 & Mt \\
\hline 14 & \multicolumn{4}{|c|}{ Voltage-dependent anion-selective channel protein 2} & Q60930 & Mt \\
\hline 15 & \multicolumn{4}{|c|}{ Heat shock protein $75 \mathrm{kDa}$, mitochondrial precursor } & Q9CQN1 & Mt \\
\hline 16 & \multicolumn{4}{|c|}{ Aconitate hydratase, mitochondrial precursor } & Q99KI0 & Mt \\
\hline 16 & \multicolumn{4}{|c|}{ Aconitate hydratase, mitochondrial precursor } & Q99KI0 & Mt \\
\hline 16 & \multicolumn{4}{|c|}{ Aconitate hydratase, mitochondrial precursor } & Q99KI0 & Mt \\
\hline 17 & \multicolumn{4}{|c|}{ Voltage-dependent anion-selective channel protein 3} & Q60931 & Mt \\
\hline 17 & \multicolumn{4}{|c|}{ Voltage-dependent anion-selective channel protein 3} & Q60931 & Mt \\
\hline 18 & Zinc finger prote & & & & Q60585 & Mt \\
\hline 19 & Cytochrome b-c & lex subunit 1 , mitocho & 1 precurso & & Q9CZ13 & Mt \\
\hline 20 & Thioredoxin-de & t peroxide reductase, & hondrial $\mathrm{p}$ & arsor & P20108 & Mt \\
\hline Spot number & Change & Protein mass/pI ${ }^{\mathrm{c}}$ & Score & Matched peptide & Sequence coverage & Expect \\
\hline & Up/down & $D a / p I$ & & & $\%$ & \\
\hline 1 & Fuse & $50,624 / 8.14$ & 60 & $15 / 52$ & 36 & 0.016 \\
\hline 2 & Fuse & $49,849 / 6.91$ & 74 & $14 / 44$ & 35 & 0.00057 \\
\hline 3 & $\mathrm{Up}$ & $10,956 / 7.93$ & 64 & $8 / 72$ & 62 & 0.0068 \\
\hline 4 & Down & $57,099 / 5.88$ & 173 & $23 / 48$ & 45 & $7.60 \mathrm{E}-14$ \\
\hline 5 & Up & $73,768 / 5.91$ & 65 & $9 / 14$ & 16 & 0.0053 \\
\hline 6 & Down & $31,330 / 6.40$ & 82 & $16 / 53$ & 44 & 0.00011 \\
\hline 7 & Down & $32,340 / 7.44$ & 60 & $9 / 43$ & 35 & 0.017 \\
\hline 8 & Down & $43,565 / 9.11$ & 96 & $18 / 36$ & 50 & $3.70 \mathrm{E}-06$ \\
\hline 9 & Down & $105,426 / 5.98$ & 60 & $16 / 45$ & 25 & 0.017 \\
\hline 10 & Down & $52,991 / 6.52$ & 196 & $27 / 45$ & 51 & $3.80 \mathrm{E}-16$ \\
\hline 11 & Up & $55,378 / 6.55$ & 60 & $11 / 33$ & 26 & 0.018 \\
\hline 12 & Up & $38,475 / 8.95$ & 76 & $11 / 34$ & 39 & 0.00037 \\
\hline 13 & Up & $35,330 / 8.62$ & 77 & $13 / 44$ & 45 & 0.00031 \\
\hline 14 & Down & $32,340 / 7.44$ & 68 & $9 / 35$ & 35 & 0.0026 \\
\hline 15 & Up & $80,501 / 6.25$ & 76 & $16 / 38$ & 25 & 0.00041 \\
\hline 16 & Up & $86,151 / 8.08$ & 55 & $11 / 32$ & 19 & 0.05 \\
\hline 16 & $\mathrm{Up}$ & $86,151 / 8.08$ & 130 & $18 / 32$ & 31 & $1.50 \mathrm{E}-09$ \\
\hline 16 & $\mathrm{Up}$ & $86,151 / 8.08$ & 124 & $21 / 44$ & 36 & $6.10 \mathrm{E}-09$ \\
\hline 17 & Down & $31,076 / 8.96$ & 83 & $13 / 54$ & 48 & $7.10 \mathrm{E}-05$ \\
\hline 17 & Down & $31,076 / 8.96$ & 105 & $15 / 46$ & 49 & $4.80 \mathrm{E}-07$ \\
\hline 18 & Down & $64,496 / 9.32$ & 60 & $13 / 51$ & 31 & 0.015 \\
\hline 19 & Devide & $53,420 / 5.75$ & 92 & $18 / 41$ & 25 & $1.00 \mathrm{E}-05$ \\
\hline 20 & Up & $28,337 / 7.15$ & 60 & $10 / 48$ & 31 & 0.015 \\
\hline
\end{tabular}

${ }^{\mathrm{a}}$ Each protein spot in Fig. 1B was identified based on mass spectra of tryptic peptides obtained by MALDI-TOF mass spectrometry.

${ }^{\mathrm{b}}$ Accession numbers of the identified protein spots were obtained from the Swiss-Prot data base.

'Theoretical molecular mass (Da) and $\mathrm{pI}$.

of dopaminergic neurons. Our laboratory has also proposed that ROS is one of the initial triggers leading to activation of apoptotic signaling following 6-OHDA treatment. In consi- deration of previous studies by others indicating that ROS affects various mitochondrial proteins in their expression, location, or modification [37-40], therefore, the goal of the present 
study was to identify alteration in the mitochondrial proteins of MN9D dopaminergic neuronal cells following 6-OHDA treatment. For this purpose, we utilized a conventional 2-DE in conjunction with a mass spectrometry. More specifically, using fractionated mitochondrial lysates of 6-OHDA-treated MN9D cells, comparative proteome analyses between 6-OHDAtreated and untreated control samples were performed through integrated technologies including protein separation by 2-DE and identification by matrix assisted laser desorption/ionizing time of flight (MALDI-TOF) mass spectrometry. Among the altered proteins, 73 protein spots were initially subjected to in-gel digestion with trypsin, MALDI-TOF mass spectrometry and a database search using either the NCBI or SWISS-PROT database. Among these identified protein spots, expression of 20 protein spots was significantly changed with p-value of less than 0.05 $(n>3)$. Table 1 summarizes these altered mitochondrial proteins in MN9D cells with accession number, their change in expression levels, score, molecular weight/pI, matched peptide number and sequence coverage. Proteins that increased or decreased in their intensity following Coomassie Brilliant Blue staining were listed. In addition, two protein spots that were fused were also listed in Table 1. These included 2-oxoisovalerate dehydrogenase subunit alpha (spot number \# 1; Bckdha) and acyl-coenzyme A thioesterase 2 (spot number \#2; Acot2). Subsequently, we further confirmed the expression levels of these identified proteins in the mitochondrial and the cytosolic fraction by immunoblot analysis. As shown in Fig. 1, many of the identified proteins seemed to be released into the cytosol following 6-OHDA treatment. These included Aco2 (spot number 16 in Table 1), Cpn10 (spot number 3), Grp75 (spot number 5), and TRAP1 (spot number 15). Unlike these proteins, several of the mitochondrial proteins that were decreased in the mitochondria after 6-OHDA treatment, were not detected in the cytosol. This may suggest the existence of alternative clearance pathway in the mitochondria after drug treatment.

Heat shock protein 75 is a mitochondrial protein that in human is encoded by the gene called tumor necrosis factor receptorassociated protein 1 (TRAP1). TRAP1 is known to play roles as ROS antagonist and chaperone [41-45]. Recently, it attracts much attention due to its close connection with PD-linked protein, PINK1 [46]. Based on the protein profiling data (Fig. 1 and
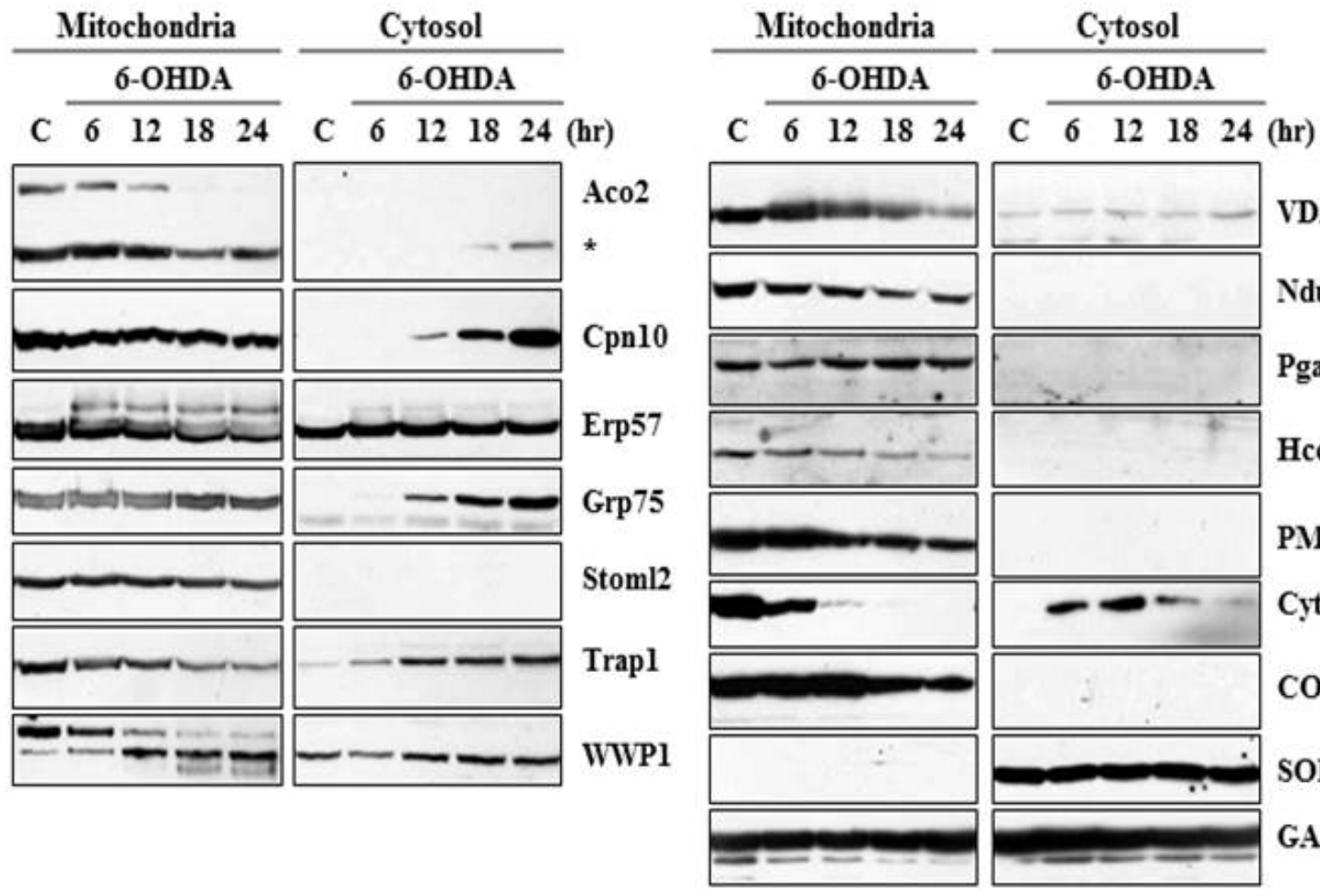

VDAC2

Ndufs2

Pgaml

Hecs

PMPCB

CytC

COXIV

SOD-1

GAPDH

Fig. 1. Immunoblot analysis of the identified protein expression in the mitochondrial and cytosolic fractions. MN9D cells were treated with or without $100 \mu \mathrm{M}$ 6-OHDA for the indicated time periods and subjected to cellular fractionation (mitochondria and cytosol). The fractionated lysates were separated on $8 \sim 12 \%$ SDS-PAGE and subjected to immunoblot analyses using antibodies that specifically recognize corresponding proteins. Anticytochrome $\mathrm{c}$ antibody (CytC) was used as a positive control in that release of cytochrome $\mathrm{c}$ into the cytosol was induced during 6-OHDA-mediated apoptosis. The following antibodies were utilized as controls; COXIV (mitochondrial marker), SOD-1 (cytosolic marker), and GAPDH (loading control). 
Table 1), we were very much interested in analyzing expression and distribution pattern of TRAP1 protein following 6-OHDA treatment. To meet this end, MN9D cells were treated with 6-OHDA for the time periods indicated, and subjected to cellular fractionation followed by an immunoblot analysis using antiTRAP1 antibody. As shown in Fig. 2A, mitochondrial expression level of TRAP1 was slightly decreased whereas its cytosolic expression level was increased in a time-dependent manner. Increased expression pattern of TRAP1 in the cytosolic fraction was also confirmed through mini-2DE (7-cm strip; Fig. 2B), suggesting that TRAP1 may be released form the mitochondria into the cytosol upon exposure to 6-OHDA. This phenomenon was accompanied with slight decrease in total expression level of TRAP1 (right panel of Fig.2A). Because increased oxidative stress leads to protein misfolding and aggregation [47], both Triton $\mathrm{X}$-100-soluble and -insoluble fraction obtained from the control and drug-treated MN9D cells were subjected to an immunoblot analysis. As expected, expression level of TRAP1 was increased in

A
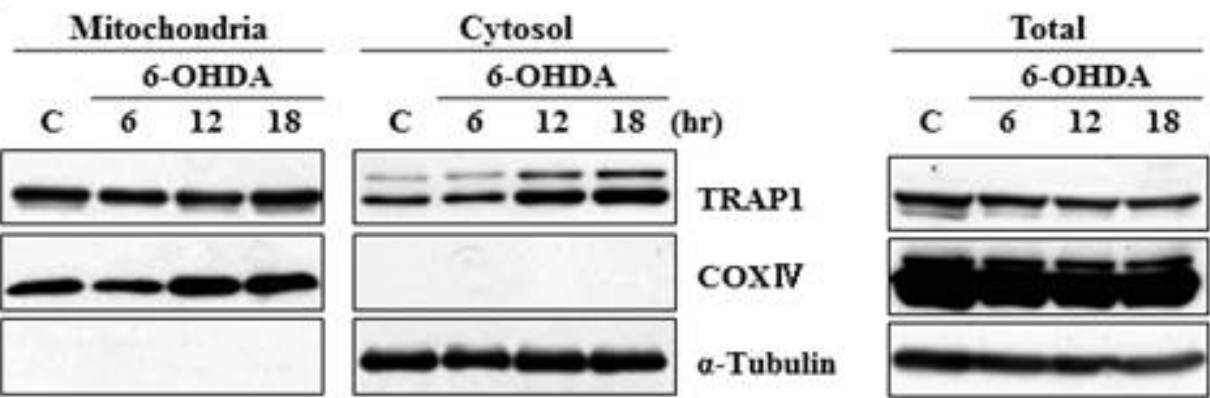

TRAP1

TRAP1

(L/E)

GAPDH

\section{B}

\section{C}

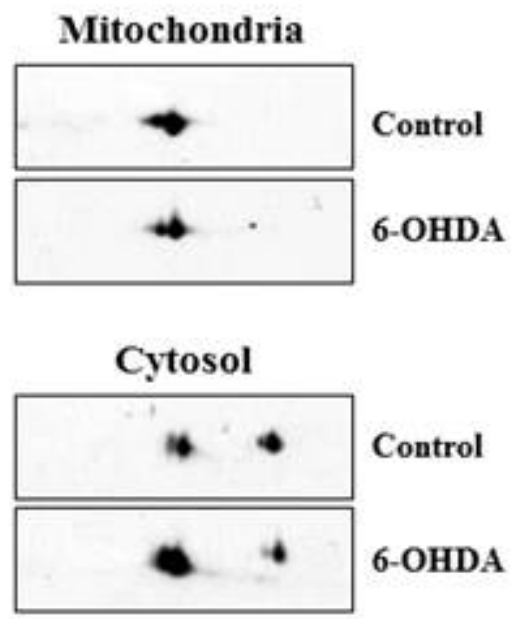

$\frac{\text { TX-100 Sol. }}{\text { C } \frac{\text { 6-OHDA }}{12 \quad 18} \text { NAC }} \frac{\text { TX-100 Insol. }}{\frac{6-O H D A}{1218} \text { NAC (hr) }}$

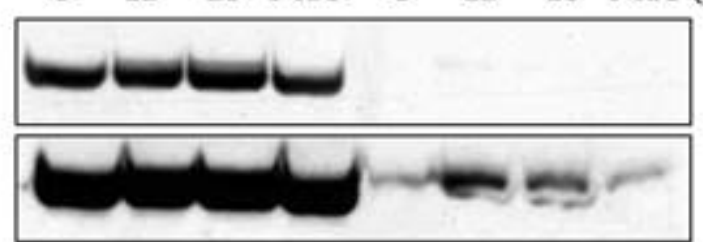

TRAPI

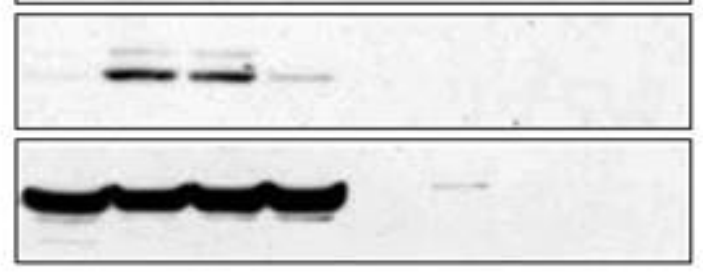

TRAPI

(L/E)

Cleaved

Cas-3

Fig. 2. Characterization of TRAP1 release in MN9D cells following 6-OHDA treatment. (A) MN9D cells were treated with or without $100 \mu \mathrm{M}$ 6-OHDA for the indicated time periods and subjected to cellular fractionation. Total and fractionated lysates were separated on SDS-PAGE and analyzed for TRAP1 expression using anti-TRAP1 antibody. Anti- $\alpha$-tubulin antibody was used as a cytosolic marker. (B) MN9D cells were treated with $100 \mu \mathrm{M}$ 6-OHDA for $18 \mathrm{hr}$ and the fractionated samples were separated on mini 2-DE (7-cm strip) and analyzed for TRAP1 expression with the specific antibody. (C) Cellular lysates obtained from MN9D cells treated with or without $100 \mu \mathrm{M}$ 6-OHDA in the presence or the absence of $2 \mathrm{mM}$ $\mathrm{N}$-acetylcysteine (NAC). Cells were then subjected to separate 1\% Triton X-100-soluble from Triton X-100-insoluble fractions. Blots were probed with mouse anti-TRAP1 antibody. Anti-caspase-3 antibody was used to demonstrate drug-induced apoptotic death. 
the Triton X-100-insoluble fraction following 6-OHDA treatment (Fig. 2C). Decreased expression patterns of TRAP1 in total lysates may be due to 6-OHDA-induced proteins transfer to the Triton $\mathrm{X}$-100-insoluble fraction. This phenomenon was reversed in the presence of $\mathrm{N}$-acetylcysteine (NAC), a widely used antioxidant. From an immunocytochemical labeling of TRAP1, we verified the punctated staining patterns of TRAP1 in the untreated control MN9D cells, indicating that TRAP1 is predominantly present in the mitochondria (Fig. 3A). This was confirmed by a double immunelabeling with anti-Tom20 (a mitochondrial marker) and anti-TRAP1. In contrast, TRAP1 showed a diffuse and dense staining pattern following 6-OHDA treatment in MN9D cells. This was quite reminiscent of those found in 6-OHDAmediated cytochrome $c$ release into the cytosol [48]. To further confirm whether 6-OHDA triggers cytosolic release of TRAP1 in primary cultures of mesencephalic dopaminergic neurons, a double immunofluorescent labeling was performed using antiTRAP1 and anti-tyrosine hydroxylase (TH), a rate-limiting enzyme of dopamine biosynthesis. We also observed 6-OHDAinduced release of TRAP1 in tyrosine hydroxylase (TH)-positive dopaminergic neuron (Fig. 3B). Taken together, data indicated that TRAP1 was released from the mitochondria into the cytosol in MN9D cells as well as primary cultures of dopaminergic neurons following 6-OHDA treatment. Intriguingly, this phenomenon was not appeared in other cell death induced by staurosporine (Fig. 4A) and etoposide (Fig. 4B). As shown in Fig. 5, a double immunofluorescent labelling indicated that TRAP1 expression pattern in MN9D cells treated with either staurosporine or etoposide quite differed from that in 6-OHDA-treated cells. Taken together, our data indicated that release of TRAP1 into the cytosol is drug-specific.

TRAP1 was initially identified as an interactive protein that
A

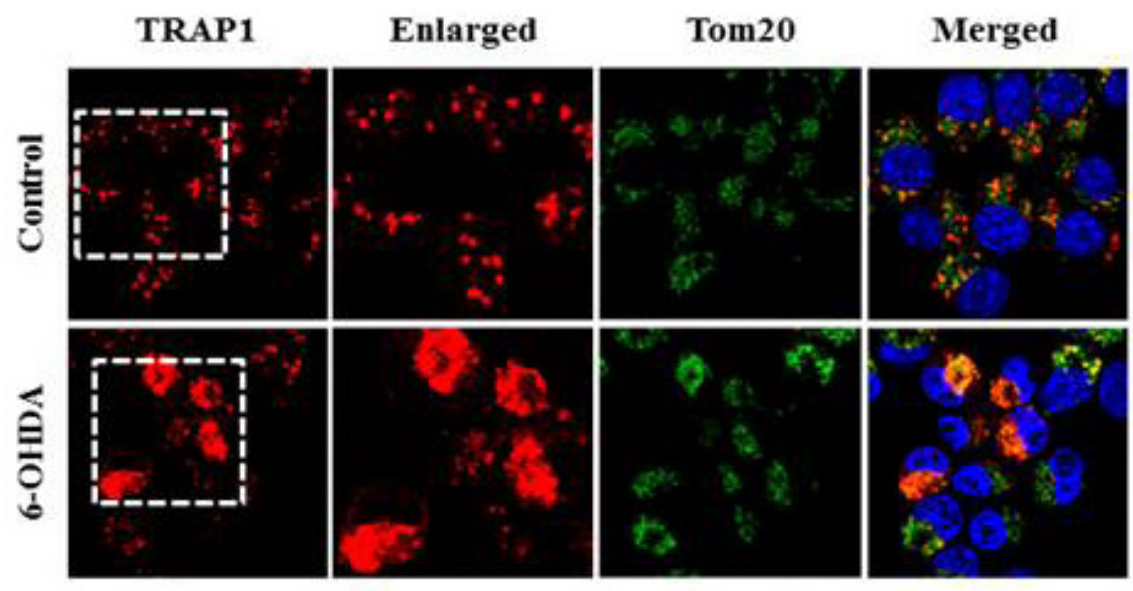

B
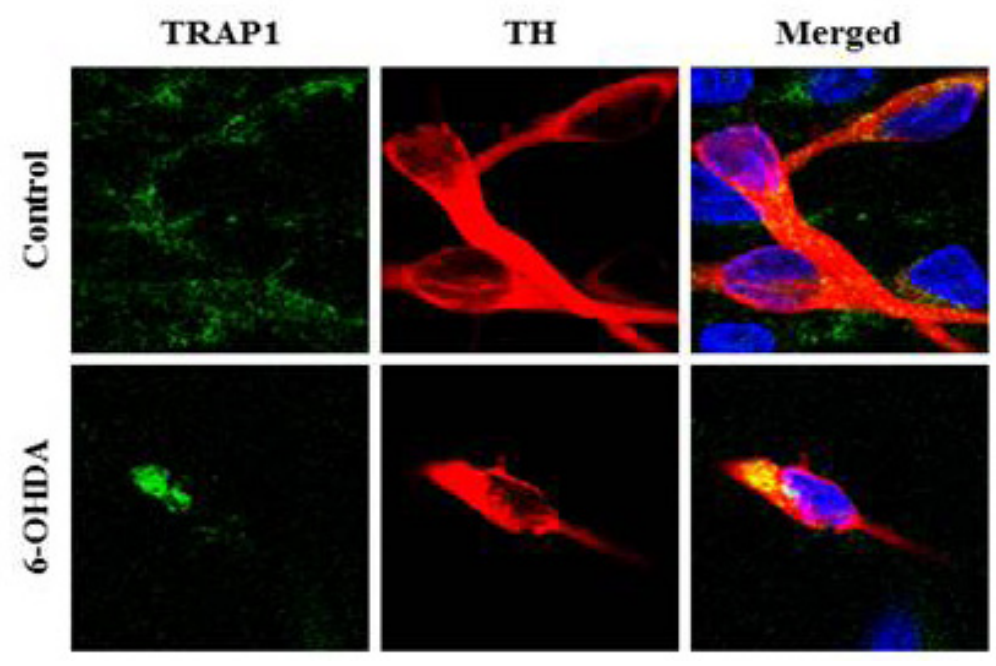

http://dx.doi.org/10.5607/en.2014.23.1.65
Fig. 3. Immunocytochemical localization of TRAP1 following 6-OHDA treatment. Mitochondrial release of TRAP1 into the cytosol was examined in (A) MN9D cells, and (B) in primary cultures of mesencephalic dopaminergic neurons. Cultures were treated with or without 20 100 $\mu \mathrm{M}$ 6-OHDA for $18 \mathrm{hr}$. Cells were stained with anti-TRAP1, anti-Tom20 (an outer mitochondrial membrane protein, mitochondrial marker), anti-TH (dopaminergic neuron marker) antibodies. Hoechst 33258 was used as a counter staining probe to mark the nuclei. 
A

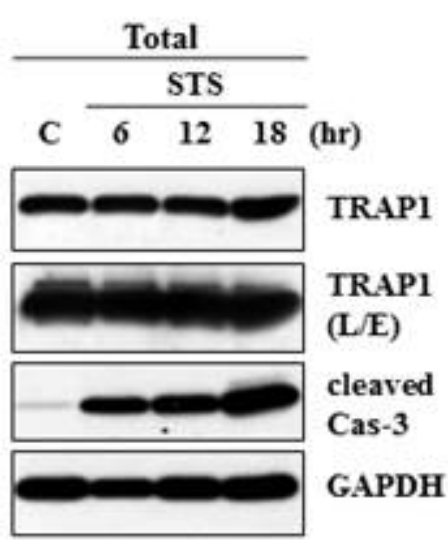

B

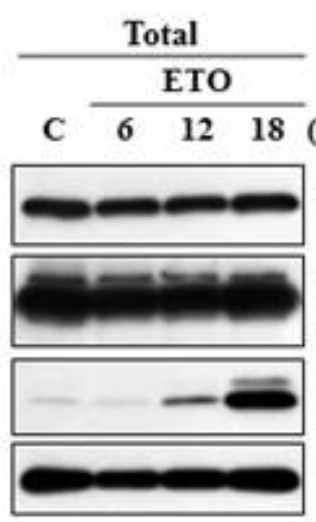

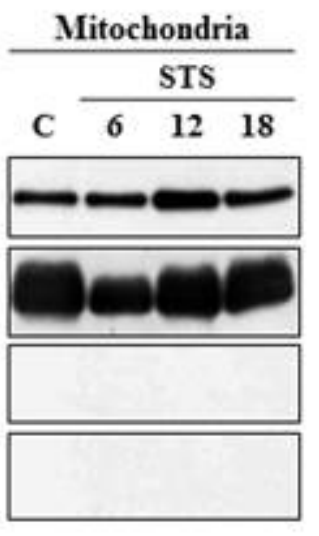
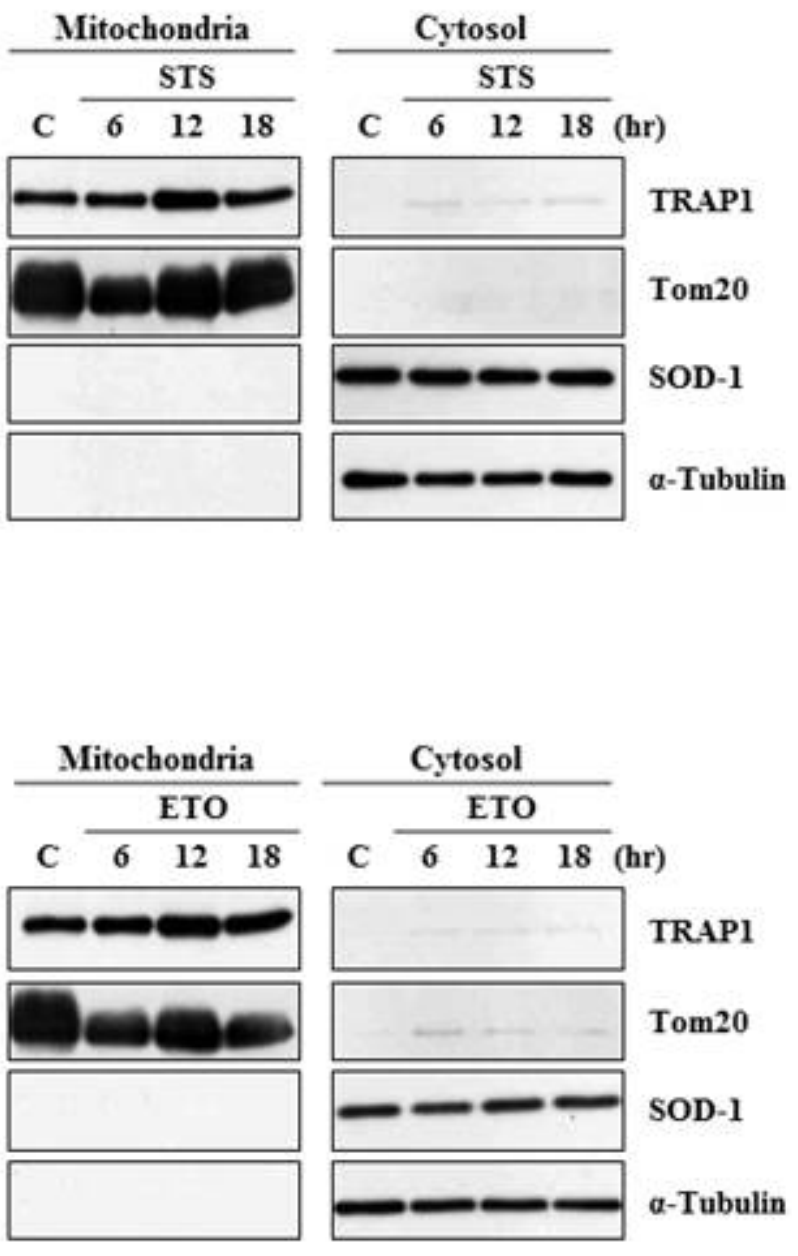

Fig. 4. Characterization of TRAP1 release in MN9D cells following treatment with other apoptosis-inducing drugs. MN9D cells were treated with or without (A) $1 \mu \mathrm{M}$ staurosporine (STS) or (B) $100 \mu \mathrm{M}$ etoposide (ETO) for the indicated time periods and subjected to cellular fractionation (mitochondria and cytosol). Total and fractionated lysates were separated on SDS-PAGE and probed with anti-TRAP1 antibody.

binds to the intracellular domain of TNFR1 in vitro [49]. TRAP1 is localized in the mitochondria and the member of the HSP90 family $[41,50,51]$. It possesses ATPase activity as well as chaperone activity. TRAP1 is shown to be induced by various environmental stresses. These include glucose deprivation, oxidative injury, and ultraviolet A irradiation. In these conditions, TRAP1 acts as a mitochondrial chaperone and plays an essential role for maintaining mitochondrial function and regulating cellular apoptosis [43, 46, 52, 53]. Consequently, overexpression of TRAP1 has been shown to protect cells from apoptotic death caused by mitochondrial dysfunction, oxidative stress, and ischemic injury in the brain and in the heart $[45,52]$. Recently, the possibility of interrelationship between TRAP1 and Parkinson's disease has raised because TRAP1 was identified as a substrate of PTEN-induced putative kinase 1 (PINK1), one of the familial Parkinson's disease genes [54, 55]. PINK1 promotes cell survival against oxidative stress by phosphorylating TRAP1 and that is impaired by PD-linked PINK1 G309D, L347P, and W437X mutations [46]. Another identified protein called Grp75 is also a molecular chaperone primarily located in the mitochondria, where it functions to maintain mitochondrial homeostasis and antagonize oxidative stress injury. Therefore, knockdown of Grp75 induces mitochondrial dysfunction and it is rescued by Parkin [56]. Moreover, expression level of Grp75 is reduced and its interaction with another PD-associated protein DJ-1 is also diminished in the affected brain regions of PD patients. Recently, two amino acid exchanges in the ATPase domain (R126W) and the substratebinding domain (P509S) of Grp75 in Spanish PD patients and other variant (A476T) in the substrate-binding domain in German PD patients were identified [57-60]. Unfortunately, all of those studies listed above did not examine a potentially distinct functional role for these proteins in the mitochondrial and the 

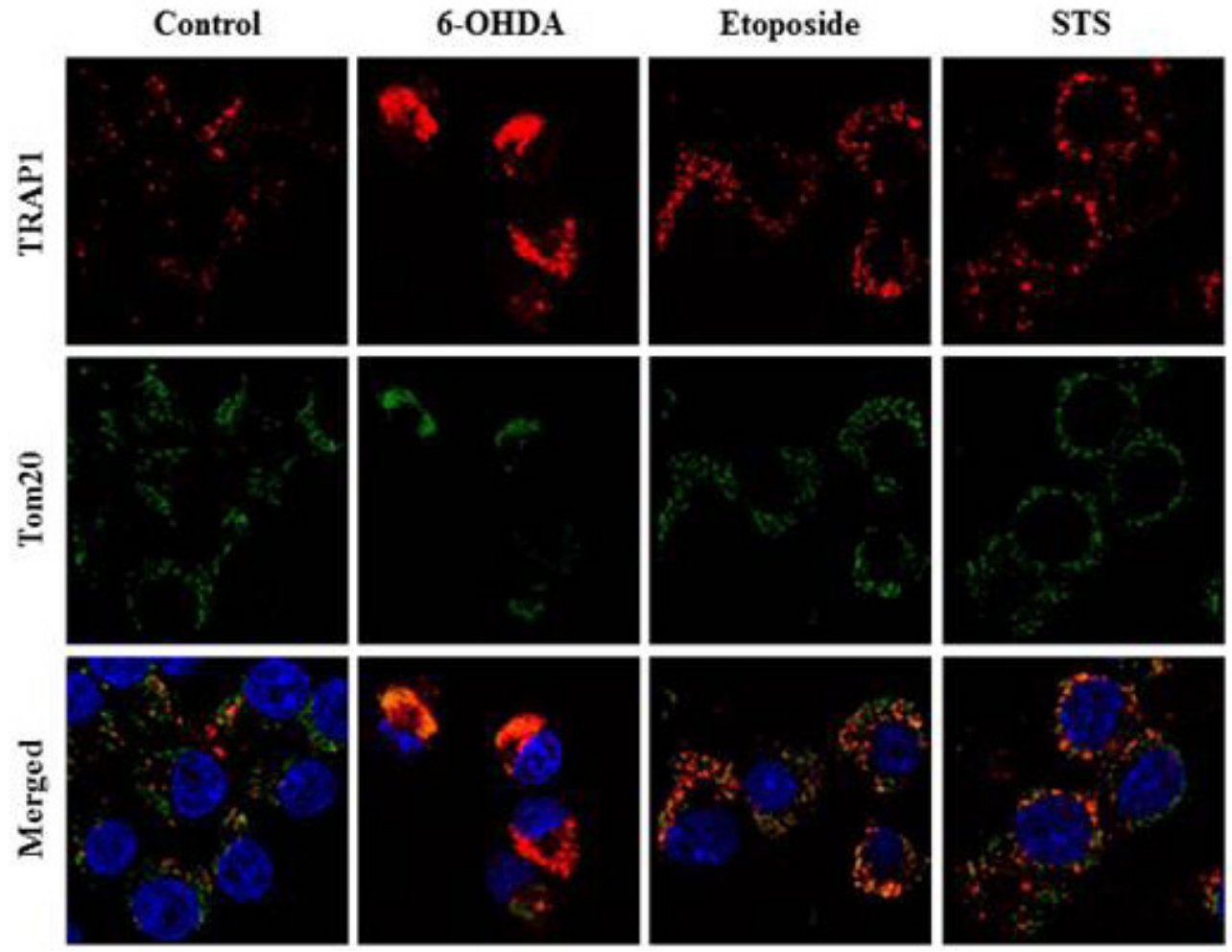

Fig. 5. Comparison of TRAP1 release patterns in MN9D cells following treatment with various apoptosis-inducing drugs. MN9D cells were treated with $100 \mu \mathrm{M}$ 6-OHDA, $1 \mu \mathrm{M}$ staurosporine (STS) or $100 \mu \mathrm{M}$ etoposide for 18 hr. Cells were then subjected to an immunocytochemical localization of TRAP1 using anti-TRAP1 antibody.

cytosolic fraction. Therefore, further study aiming to this end may disclose a dynamic role for these proteins and their interplay with the known PD-related proteins. More specifically, there are several other points to be addressed to understand the significance and importance of drug-induced release of the mitochondrial proteins. For example, it is intriguing to investigate i) how the cytosolic TRAP1 regulates a functional role for the cytosolic PDrelated proteins; ii) how drug-induced TRAP1 release is related to cell death, and iii) what other unidentified regulators or signaling pathways are also critically involved in these events. With these and many other unanswered questions in mind, further elucidation of the role of the TRAP1 at the molecular and cellular levels could contribute to our understanding of the pathogenesis of Parkinson's disease.

\section{ACKNOWLEDGEMENTS}

This work was supported from the Ministry for Health, Welfare and Family Affairs (A111382).

\section{REFERENCES}

1. Mizuno Y, Ohta S, Tanaka M, Takamiya S, Suzuki K, Sato T, Oya H, Ozawa T, Kagawa Y (1989) Deficiencies in complex I subunits of the respiratory chain in Parkinson's disease.
Biochem Biophys Res Commun 163:1450-1455.

2. Schapira AH (1993) Mitochondrial complex I deficiency in Parkinson's disease. Adv Neurol 60:288-291.

3. Schapira AH, Cooper JM, Dexter D, Jenner P, Clark JB, Marsden CD (1989) Mitochondrial complex I deficiency in Parkinson's disease. Lancet 1:1269.

4. Bindoff LA, Birch-Machin MA, Cartlidge NE, Parker WD Jr, Turnbull DM (1991) Respiratory chain abnormalities in skeletal muscle from patients with Parkinson's disease. J Neurol Sci 104:203-208.

5. Krige D, Carroll MT, Cooper JM, Marsden CD, Schapira AH (1992) Platelet mitochondrial function in Parkinson's disease. The Royal Kings and Queens Parkinson Disease Research Group. Ann Neurol 32:782-788.

6. Piccoli C, Sardanelli A, Scrima R, Ripoli M, Quarato G, D’Aprile A, Bellomo F, Scacco S, De Michele G, Filla A, Iuso A, Boffoli D, Capitanio N, Papa S (2008) Mitochondrial respiratory dysfunction in familiar parkinsonism associated with PINK1 mutation. Neurochem Res 33:2565-2574.

7. Gandhi S, Wood-Kaczmar A, Yao Z, Plun-Favreau H, Deas E, Klupsch K, Downward J, Latchman DS, Tabrizi SJ, Wood NW, Duchen MR, Abramov AY (2009) PINK1-associated Parkinson's disease is caused by neuronal vulnerability to calcium-induced cell death. Mol Cell 33:627-638.

8. Yang Y, Gehrke S, Imai Y, Huang Z, Ouyang Y, Wang JW, Yang L, 
Beal MF, Vogel H, Lu B (2006) Mitochondrial pathology and muscle and dopaminergic neuron degeneration caused by inactivation of Drosophila Pink1 is rescued by Parkin. Proc Natl Acad Sci U S A 103:10793-10798.

9. Poole AC, Thomas RE, Andrews LA, McBride HM, Whitworth AJ, Pallanck LJ (2008) The PINK1/Parkin pathway regulates mitochondrial morphology. Proc Natl Acad Sci U S A 105:1638-1643.

10. Deas E, Plun-Favreau H, Wood NW (2009) PINK1 function in health and disease. EMBO Mol Med 1:152-165.

11. Weihofen A, Thomas KJ, Ostaszewski BL, Cookson MR, Selkoe DJ (2009) Pink1 forms a multiprotein complex with Miro and Milton, linking Pink1 function to mitochondrial trafficking. Biochemistry 48:2045-2052.

12. Valente EM, Abou-Sleiman PM, Caputo V, Muqit MM, Harvey K, Gispert S, Ali Z, Del Turco D, Bentivoglio AR, Healy DG, Albanese A, Nussbaum R, González-Maldonado R, Deller T, Salvi S, Cortelli P, Gilks WP, Latchman DS, Harvey RJ, Dallapiccola B, Auburger G, Wood NW (2004) Hereditary early-onset Parkinson's disease caused by mutations in PINK1. Science 304:1158-1160.

13. Biskup S, Moore DJ, Celsi F, Higashi S, West AB, Andrabi SA, Kurkinen K, Yu SW, Savitt JM, Waldvogel HJ, Faull RL, Emson PC, Torp R, Ottersen OP, Dawson TM, Dawson VL (2006) Localization of LRRK2 to membranous and vesicular structures in mammalian brain. Ann Neurol 60:557-569.

14. Kim Y, Park J, Kim S, Song S, Kwon SK, Lee SH, Kitada T, Kim JM, Chung J (2008) PINK1 controls mitochondrial localization of Parkin through direct phosphorylation. Biochem Biophys Res Commun 377:975-980.

15. Shavali S, Brown-Borg HM, Ebadi M, Porter J (2008) Mitochondrial localization of alpha-synuclein protein in alpha-synuclein overexpressing cells. Neurosci Lett 439:125128.

16. Junn E, Jang WH, Zhao X, Jeong BS, Mouradian MM (2009) Mitochondrial localization of DJ-1 leads to enhanced neuroprotection. J Neurosci Res 87:123-129.

17. Meriin AB, Sherman MY (2005) Role of molecular chaperones in neurodegenerative disorders. Int J Hyperthermia 21:403-419.

18. Berke SJ, Paulson HL (2003) Protein aggregation and the ubiquitin proteasome pathway: gaining the UPPer hand on neurodegeneration. Curr Opin Genet Dev 13:253-261.

19. Grünblatt E, Mandel S, Jacob-Hirsch J,Zeligson S, Amariglo N, Rechavi G, Li J, Ravid R, Roggendorf W, Riederer P, Youdim MB (2004) Gene expression profiling of parkinsonian substantia nigra pars compacta; alterations in ubiquitin- proteasome, heat shock protein, iron and oxidative stress regulated proteins, cell adhesion/cellular matrix and vesicle trafficking genes. J Neural Transm 111:1543-1573.

20. Zhang Y, James M, Middleton FA, Davis RL (2005) Transcriptional analysis of multiple brain regions in Parkinson's disease supports the involvement of specific protein processing, energy metabolism, and signaling pathways, and suggests novel disease mechanisms. Am J Med Genet B Neuropsychiatr Genet 137B:5-16.

21. Choudhary J, Grant SG (2004) Proteomics in postgenomic neuroscience: the end of the beginning. Nat Neurosci 7:440445.

22. Fountoulakis M, Kossida S (2006) Proteomics-driven progress in neurodegeneration research. Electrophoresis 27:1556-1573.

23. Pienaar IS, Daniels WM, Götz J (2008) Neuroproteomics as a promising tool in Parkinson's disease research. J Neural Transm 115:1413-1430.

24. Licker V, Kövari E, Hochstrasser DF, Burkhard PR (2009) Proteomics in human Parkinson's disease research. J Proteomics 73:10-29.

25. Basso M, Giraudo S, Corpillo D, Bergamasco B, Lopiano L, Fasano M (2004) Proteome analysis of human substantia nigra in Parkinson's disease. Proteomics 4:3943-3952.

26. Jin J, Hulette C, Wang Y, Zhang T, Pan C, Wadhwa R, Zhang J (2006) Proteomic identification of a stress protein, mortalin/ mthsp70/GRP75: relevance to Parkinson disease. Mol Cell Proteomics 5:1193-1204.

27. Van Laar VS, Dukes AA, Cascio M, Hastings TG (2008) Proteomic analysis of rat brain mitochondria following exposure to dopamine quinone: implications for Parkinson disease. Neurobiol Dis 29:477-489.

28. Zhang J, Sokal I, Peskind ER, Quinn JF, Jankovic J, Kenney C, Chung KA, Millard SP, Nutt JG, Montine TJ (2008) CSF multianalyte profile distinguishes Alzheimer and Parkinson diseases. Am J Clin Pathol 129:526-529.

29. Jin J, Meredith GE, Chen L, Zhou Y, Xu J, Shie FS, Lockhart P, Zhang J (2005) Quantitative proteomic analysis of mitochondrial proteins: relevance to Lewy body formation and Parkinson's disease. Brain Res Mol Brain Res 134:119138.

30. Diedrich M, Mao L, Bernreuther C, Zabel C, Nebrich G, Kleene R, Klose J (2008) Proteome analysis of ventral midbrain in MPTP-treated normal and L1cam transgenic mice. Proteomics 8:1266-1275.

31. Lee YM, Park SH, Chung KC, Oh YJ (2003) Proteomic analysis reveals upregulation of calreticulin in murine 
dopaminergic neuronal cells after treatment with 6-hydroxydopamine. Neurosci Lett 352:17-20.

32. Lee YM, Park SH, Shin DI, Hwang JY, Park B, Park YJ, Lee TH, Chae HZ, Jin BK, Oh TH, Oh YJ (2008) Oxidative modification of peroxiredoxin is associated with druginduced apoptotic signaling in experimental models of Parkinson disease. J Biol Chem 283:9986-9998.

33. De Iuliis A, Grigoletto J, Recchia A, Giusti P, Arslan P (2005) A proteomic approach in the study of an animal model of Parkinson's disease. Clin Chim Acta 357:202-209.

34. Nakamura M, Yamada M, Ohsawa T, Morisawa H, Nishine T, Nishimura O, Toda T (2006) Phosphoproteomic profiling of human SH-SY5Y neuroblastoma cells during response to 6-hydroxydopamine-induced oxidative stress. Biochim Biophys Acta 1763:977-989.

35. Valastro B, Dekundy A, Krogh M, Lundblad M, James P, Danysz W, Quack G, Cenci MA (2007) Proteomic analysis of striatal proteins in the rat model of L-DOPA-induced dyskinesia. J Neurochem 102:1395-1409.

36. McLaughlin P, Zhou Y, Ma T, Liu J, Zhang W, Hong JS, Kovacs M, Zhang J (2006) Proteomic analysis of microglial contribution to mouse strain-dependent dopaminergic neurotoxicity. Glia 53:567-582.

37. van Loo G, Schotte P, van Gurp M, Demol H, Hoorelbeke B, Gevaert K, Rodriguez I, Ruiz-Carrillo A, Vandekerckhove J, Declercq W, Beyaert R, Vandenabeele P (2001) Endonuclease G: a mitochondrial protein released in apoptosis and involved in caspase-independent DNA degradation. Cell Death Differ 8:1136-1142.

38. Arnoult D, Gaume B, Karbowski M, Sharpe JC, Cecconi F, Youle RJ (2003) Mitochondrial release of AIF and EndoG requires caspase activation downstream of Bax/Bak-mediated permeabilization. EMBO J 22:4385-4399.

39. Goldstein JC, Muñoz-Pinedo C, Ricci JE, Adams SR, Kelekar A, Schuler M, Tsien RY, Green DR (2005) Cytochrome c is released in a single step during apoptosis. Cell Death Differ 12:453-462.

40. Precht TA, Phelps RA, Linseman DA, Butts BD, Le SS, Laessig TA, Bouchard RJ, Heidenreich KA (2005) The permeability transition pore triggers Bax translocation to mitochondria during neuronal apoptosis. Cell Death Differ 12:255-265.

41. Chen CF, Chen Y, Dai K, Chen PL, Riley DJ, Lee WH (1996) A new member of the hsp90 family of molecular chaperones interacts with the retinoblastoma protein during mitosis and after heat shock. Mol Cell Biol 16:4691-4699.

42. Montesano Gesualdi N, Chirico G, Pirozzi G, Costantino E, Landriscina M, Esposito F (2007) Tumor necrosis factor- associated protein 1 (TRAP-1) protects cells from oxidative stress and apoptosis. Stress 10:342-350.

43. Hua G, Zhang Q, Fan Z (2007) Heat shock protein 75 (TRAP1) antagonizes reactive oxygen species generation and protects cells from granzyme M-mediated apoptosis. J Biol Chem 282:20553-20560.

44. Im CN, Lee JS, Zheng Y, Seo JS (2007) Iron chelation study in a normal human hepatocyte cell line suggests that tumor necrosis factor receptor-associated protein 1 (TRAP1) regulates production of reactive oxygen species. J Cell Biochem 100:474-486.

45. Xu L, Voloboueva LA, Ouyang Y, Emery JF, Giffard RG (2009) Overexpression of mitochondrial Hsp70/Hsp75 in rat brain protects mitochondria, reduces oxidative stress, and protects from focal ischemia. J Cereb Blood Flow Metab 29:365-374.

46. Pridgeon JW, Olzmann JA, Chin LS, Li L (2007) PINK1 protects against oxidative stress by phosphorylating mitochondrial chaperone TRAP1. PLoS Biol 5:e172.

47. Bandopadhyay R, de Belleroche J (2010) Pathogenesis of Parkinson's disease: emerging role of molecular chaperones. Trends Mol Med 16:27-36.

48. Han BS, Hong HS, Choi WS, Markelonis GJ, Oh TH, Oh YJ (2003) Caspase-dependent and -independent cell death pathways in primary cultures of mesencephalic dopaminergic neurons after neurotoxin treatment. J Neurosci 23:5069-5078.

49. Song HY, Dunbar JD, Zhang YX, Guo D, Donner DB (1995) Identification of a protein with homology to hsp90 that binds the type 1 tumor necrosis factor receptor. J Biol Chem 270:3574-3581.

50. Cechetto JD, Gupta RS (2000) Immunoelectron microscopy provides evidence that tumor necrosis factor receptorassociated protein 1 (TRAP-1) is a mitochondrial protein which also localizes at specific extramitochondrial sites. Exp Cell Res 260:30-39.

51. Owen BA, Sullivan WP, Felts SJ, Toft DO (2002) Regulation of heat shock protein 90 ATPase activity by sequences in the carboxyl terminus. J Biol Chem 277:7086-7091.

52. Voloboueva LA, Duan M, Ouyang Y, Emery JF, Stoy C, Giffard RG (2008) Overexpression of mitochondrial Hsp70/Hsp75 protects astrocytes against ischemic injury in vitro. J Cereb Blood Flow Metab 28:1009-1016.

53. Landriscina M, Amoroso MR, Piscazzi A, Esposito F (2010) Heat shock proteins, cell survival and drug resistance: the mitochondrial chaperone TRAP1, a potential novel target for ovarian cancer therapy. Gynecol Oncol 117:177-182.

54. Abeliovich A (2007) Parkinson's disease: pro-survival effects of PINK1. Nature 448:759-760. 
55. Kroemer G, Blomgren K (2007) Mitochondrial cell death control in familial Parkinson disease. PLoS Biol 5:e206.

56. Yang H, Zhou X, Liu X, Yang L, Chen Q, Zhao D, Zuo J, Liu W (2011) Mitochondrial dysfunction induced by knockdown of mortalin is rescued by Parkin. Biochem Biophys Res Commun 410:114-120.

57. Kaul SC, Deocaris CC, Wadhwa R (2007) Three faces of mortalin: a housekeeper, guardian and killer. Exp Gerontol 42:263-274.

58. Deocaris CC, Kaul SC, Wadhwa R (2008) From proliferative to neurological role of an hsp70 stress chaperone, mortalin. Biogerontology 9:391-403.
59. Burbulla LF, Schelling C, Kato H, Rapaport D, Woitalla D, Schiesling C, Schulte C, Sharma M, Illig T, Bauer P, Jung S, Nordheim A, Schöls L, Riess O, Krüger R (2010) Dissecting the role of the mitochondrial chaperone mortalin in Parkinson's disease: functional impact of disease-related variants on mitochondrial homeostasis. Hum Mol Genet 19:4437-4452.

60. Chiasserini D, Tozzi A, de Iure A, Tantucci M, Susta F, Orvietani PL, Koya K, Binaglia L, Calabresi P (2011) Mortalin inhibition in experimental Parkinson's disease. Mov Disord 26:1639-1647. 